\title{
Impact of Thyrotropin Receptor Antibody Levels on Fetal Development in Two Successive Pregnancies in a Woman with Graves' Disease
}

\author{
Marit R. Bjørgaas ${ }^{\text {a, d }}$ Hanne Farstad $^{b}$ Sverre C. Christiansen ${ }^{a}$ Harm-Gerd K. Blaas ${ }^{c, e}$
}

Departments of a Endocrinology, ${ }^{b}$ Pediatrics and ${ }^{\mathrm{c}}$ Laboratory Medicine, Children's and Women's Health, St. Olavs University Hospital, and d Department of Cancer Research and Molecular Medicine and ${ }^{\mathrm{e}}$ National Center for Fetal Medicine, Norwegian University of Science and Technology, Trondheim, Norway

\section{Established Facts}

- Thyrotropin receptor antibodies (TRAb) tend to increase after radioiodine treatment for Graves' disease.

- Transplacental passage of stimulating TRAb may lead to fetal and neonatal thyreotoxicosis in the second half of pregnancy.

- Persistent high levels of TRAb during pregnancy increases the risk for fetal and neonatal thyreotoxicosis.

\section{Novel Insights}

- This report documents transplacental passage of TRAb in two successive pregnancies in a woman who received radioiodine for Graves' disease and later underwent total thyroidectomy.

- The report illustrates the impact of maternal TRAb level for neonatal outcome in two successive pregnancies.

\section{Key Words}

Fetus - Goiter • Pregnancy • Radioactive iodine •

Thyrotoxicosis $\cdot$ Thyroid-stimulating antibodies

\begin{abstract}
Background: Treatment with radioiodine for Graves' disease regularly increases the level of antithyroid antibodies, and transplacental passage of stimulating thyrotropin receptor antibodies (TRAb) may cause fetal hyperthyroidism. Case presentation: A 21-year-old woman with Graves' disease received radioiodine treatment to avoid use of antithyroid drugs in pregnancy. She became pregnant 4 months
\end{abstract}

\section{KARGER}

E-Mail karger@karger.ch www.karger.com/hrp
(C) 2012 S. Karger AG, Basel 1663-2818/13/0791-0039\$38.00/0

Karger

Open access

This is an Open Access article licensed under the terms of the Creative Commons Attribution-NonCommercialNoDerivs 3.0 License (www.karger.com/OA-license), applicable to the online version of the article only. Distribution for non-commercial purposes only. later and was euthyroid during pregnancy. In gestational week (GW) 33, she was admitted with an increased fetal heart rate of 176-180 beats/min. Fetal echocardiography indicated cardiac decompensation. The neonate had severe hyperthyroidism (free thyroxine $>100 \mathrm{pmol} / \mathrm{l}$, nv 12.0-22.0), cardiac insufficiency, insufficient weight gain, goiter and considerably accelerated skeletal age. In the mother and neonate, TRAb was $>40 \mathrm{IU} / \mathrm{I}(\mathrm{nv}<1.0)$, indicating transplacental passage of stimulating antibodies. After delivery, TRAb remained $>40 \mathrm{lU} / \mathrm{l}$ in the woman, and 18 months later she underwent total thyroidectomy with subsequent decline in TRAb. In her next pregnancy, TRAb fluctuated between 38 and $17 \mathrm{IU} / \mathrm{l}$, and repeated fetal ultrasound showed no goiter 
or sign of hyperthyroidism. In cord blood, TRAb was 10.9 IU/I, and the neonate had normal thyroid hormone levels. Conclusion: This case report illustrates the impact of maternal TRAb level for neonatal outcome in two successive pregnancies.

Copyright @ 2012 S. Karger AG, Basel

\section{Introduction}

Graves' disease is the major cause of hyperthyroidism in pregnancy [1]. In Graves' disease, stimulating TRAb induce hypersecretion of thyroid hormones. Poor control of hyperthyroidism in pregnancy increases the risk for fetal loss, intrauterine growth restriction and preterm delivery [2]. Monotherapy with low-dose antithyroid drugs (ATD) is the preferred treatment and is associated with minimal risks for the fetus $[1,3]$. Treatment with radioactive iodine is contraindicated in pregnancy because it may ablate the fetal thyroid [4].

Women with Graves' disease are advised to avoid pregnancy until the disease is controlled and thyroid hormone levels normalized. If a nonpregnant woman prefers ablative therapy, surgery or radioidine may be considered. Women with Graves' disease who plan pregnancy were historically considered good candidates for radioiodine because after such treatment they might not need ATD but become euthyroid with levothyroxin $\left(\mathrm{LT}_{4}\right)$ replacement [5]. For reasons of radioprotection, women treated with radioiodine are advised to postpone pregnancy for 4-6 months $[1,4]$. However, radioiodine therapy regularly leads to worsening of autoimmunity with increasing TRAb $[6,7]$, and transplacental passage of stimulating TRAb in the second half of pregnancy may cause fetal hyperthyroidism [8-11]. Many women are TRAb-positive several years after radioiodine therapy $[6,8,9]$, and postponing pregnancy for 6 months after radioiodine may be insufficient with regard to the risk for fetal hyperthyroidism [12]. Therefore, in women with high TRAb titers, surgery is recommended if the woman is planning pregnancy within the first 2 years [1].

We describe a woman with Graves' disease who was treated with radioiodine and became pregnant 4 months after the last treatment. The woman has given written consent to this report. During pregnancy, maternal TRAb increased to $>40$ times the upper limit of normal (ULN). Fetal echocardiography indicated cardiac decompensation, and the neonate had severe hyperthyroidism and a TRAb level similar to the mother. Before her next pregnancy, the woman underwent total thyroidectomy, TRAb declined and fetal ultrasound showed no goiter or other sign of hyperthyroidism. The TRAb level in cord blood of the second neonate was ten times the ULN, but the neonate had normal thyroid hormone levels.

\section{Case Report}

A 21-year-old woman of Caucasian ethnicity was admitted in January 2004 because of Graves' disease with free thyroxine $\left(\mathrm{FT}_{4}\right) 41.1 \mathrm{pmol} / \mathrm{l}$ (nv 12.0-22.0), free triiodothyronine $\left(\mathrm{FT}_{3}\right) 11.3$ $\mathrm{pmol} / \mathrm{l}$ (nv 3.9-6.7), TSH <0.01 mIU/l (nv 0.27-4.20), TRAb 8.1 IU/l $(\mathrm{nv}<1.0)$ and antithyroid peroxidase $60 \mathrm{kU} / \mathrm{ml}(\mathrm{nv}<35)$. She was initially treated with ATD (carbimazole), with the addition of $\mathrm{LT}_{4}$ after 1 month, and the level of thyroid hormones normalized $\left(\mathrm{FT}_{4} 16.7-22.6 \mathrm{pmol} / \mathrm{l}\right.$ and $\left.\mathrm{FT}_{3} 5.9-5.5 \mathrm{pmol} / \mathrm{l}\right)$ while $\mathrm{TSH}$ remained suppressed $<0.01 \mathrm{mIU} / \mathrm{l}$. She was planning to become pregnant within a short time and wanted to be treated with radioiodine to avoid the use of ATD in pregnancy. After 3 months of treatment, $\mathrm{ATD}$ and $\mathrm{LT}_{4}$ were stopped, and 1 week later she received $400 \mathrm{mBq}$ of radioiodine. Carbimazole was temporarily reinstituted, and 2 weeks after radioiodine treatment she was euthyroid ( $\mathrm{FT}_{4} 16.2 \mathrm{pmol} / \mathrm{l}, \mathrm{FT}_{3} 5.9 \mathrm{pmol} / \mathrm{l}$ and TSH $\left.0.60 \mathrm{mIU} / \mathrm{l}\right)$. She relapsed after cessation of carbimazole $\left(\mathrm{FT}_{4}\right.$ approx. 29 pmol/l, $\mathrm{FT}_{3}$ approx. 9-10 $\mathrm{pmol} / \mathrm{l}$ and $\left.\mathrm{TSH}<0.01 \mathrm{mIU} / \mathrm{l}\right)$ and received a second dose of $400 \mathrm{mBq} 4$ months after the first radioiodine treatment. Subsequently, she became hypothyroid and started $\mathrm{LT}_{4}$ replacement.

The patient was advised to avoid pregnancy for at least 6 months, but became pregnant 4 months after the second radioiodine treatment. At 7 weeks of pregnancy, $\mathrm{FT}_{4}$ was $16.2 \mathrm{pmol} / \mathrm{l}$ and TSH $4.17 \mathrm{mIU} / 1$, and the dose of $\mathrm{LT}_{4}$ was increased slightly. At that time, she had developed moderate opthalmopathy, indicating increasing autoimmunity. Fetal ultrasound at gestational week (GW) $22^{+3}$ did not reveal pathology. She lived far away from the university hospital, and was intended to be followed by the local physician, but unfortunately TRAb level was not assessed. At GW $33^{+0}$ she was admitted to the obstetrical department because of increased fetal heart rate of 176-180 beats/min. Fetal echocardiography revealed a dilated right atrium, hypertrophy of the right ventricle and insufficiency of the tricuspid valve with regurgitation $(4-6 \mathrm{~m} / \mathrm{s})$. Delivery was spontaneous at $\mathrm{GW} 34^{+5}$ : a girl with birth weight $2,270 \mathrm{~g}$ (100 g below mean according to GW) [13], length $51 \mathrm{~cm}$ (+2 SD according to GW) [13] and Apgar scores 6-9-9 (1-5-10 $\mathrm{min})$. The neonate had tachycardia (230-250 beats/ min for several hours), tachypnea and cardiac insufficiency, and was transferred to the intensive care unit. Repeated echocardiography confirmed the fetal findings.

TRAb in maternal and neonatal serum was $>40 \mathrm{IU} / \mathrm{l}$. The neonate had severe hyperthyroidism with $\mathrm{FT}_{4}>100 \mathrm{pmol} / \mathrm{l}, \mathrm{FT}_{3}>50$ pmol/l and TSH $0.02 \mathrm{mIU} / \mathrm{l}$, obviously caused by transplacental passage of stimulating TRAb. Ultrasound revealed a goiter, and her skeletal age was around 6 months. She was treated with potassium iodine, ATD (carbimazole) and propranolol. Subsequently, treatment was supplemented with $\mathrm{LT}_{4}$ and carbimazole was discontinued. Her condition improved, and the echocardiographic
40

Horm Res Paediatr 2013;79:39-43 DOI: $10.1159 / 000342644$
Bjørgaas/Farstad/Christiansen/Blaas 
findings normalized, except for minor tricuspid insufficiency (2.4 $\mathrm{m} / \mathrm{s}$ ). She was discharged after 4 weeks. TRAb remained $>40 \mathrm{IU} / \mathrm{l}$ for 6 weeks, thereafter declined, and was no longer detectable at 5 months. The child was treated with $\mathrm{LT}_{4}$ until she was 3 years of age. Thereafter, she has been euthyroid and had a normal development.

The mother had persistently elevated TRAb $>40$ IU/l. She planned a new pregnancy. Eighteen months after the delivery, she underwent total thyroidectomy. The thyroid remnant was small, and histology revealed extensive fibrosis with some inflammatory changes. After thyroidectomy, TRAb declined. In her next pregnancy a year later, her thyroid hormone levels were normal and TRAb fluctuated between 38 and 17 IU/l. Fetal ultrasound at GW 20 and 36 indicated normal growth and anatomy with no sign of goiter. She delivered at GW $39^{+5}$ : a healthy girl with birth weight 3,515 g, length $51 \mathrm{~cm}$, and with normal $\mathrm{FT}_{4} 17 \mathrm{pmol} / \mathrm{l}$ and TSH $1.0 \mathrm{mIU} / \mathrm{l}$. TRAb was elevated (10.9 IU/l) in cord blood, but 3 months later undetectable in the child's serum. In the mother, TRAb increased to $>40$ IU/1 3 months after the delivery, subsequently gradually declined, but 30 months later (i.e. 87 months after the second radioiodine treatment and 54 months after total thyroidectomy) was still elevated 6.5 IU/l.

\section{Discussion}

This report documents transplacental passage of TRAb in two successive pregnancies. In the first pregnancy, maternal TRAb at delivery was $>40 \mathrm{IU} / \mathrm{l}$, fetal echocardiography indicated cardiac decompensation, the neonate had severe hyperthyroidism and TRAb in neonatal serum was $>40 \mathrm{IU} / \mathrm{l}$. After thyroidectomy, maternal TRAb levels declined, and in her next pregnancy the neonate was unaffected despite a TRAb level ten times the ULN in cord blood.

The immunoassay for TRAb used in our laboratory does not discriminate between stimulating and blocking antibodies, and the bioactivity of the serum was not tested. However, the clinical course clearly indicated that the antibodies were stimulating. Blocking TRAb may cause hypothyroidism, and a mixture of blocking and stimulating antibodies may coexist in the same patient $[14,15]$.

When a woman has been treated with radioiodine and is euthyroid on $\mathrm{LT}_{4}$ replacement, without ATD, as in this case, the risk for fetal hyperthyroidism seems to depend primarily on the maternal TRAb level $[8,11,15]$. However, fetal or neonatal hyperthyroidism may occur even with moderate TRAb elevation [11] due to the fact that TRAb bioactivity is not always proportional to the level in the assay [14].

An increase in TRAb is common after radioiodine treatment [6-8]. In the reported case, increased autoim- munity, obviously caused by prepregnancy radioiodine treatment, was accompanied by increasing opthalmopathy, but unfortunately, this was not recognized until the fetus developed severe hyperthyroidism. Fetal goiter might have been revealed by repeated thyroid ultrasound, which, in experienced hands, is a sensitive diagnostic tool with respect to fetal thyroid dysfunction $[11,16]$. If fetal hyperthyroidism had been recognized, the woman might, in addition to $\mathrm{LT}_{4}$, have been treated with ATD or iodide, which pass the placenta and block fetal hormone synthesis [11, 12, 17-19]. Fetal monitoring of such combined treatment is difficult, but fetal thyroid status and TRAb levels may be obtained by umbilical cord blood sampling (cordocentesis) $[11,19]$. This procedure may carry a risk for infection, preterm delivery and fetal death, and is recommended to be reserved for cases in which the thyroid status is unclear in a fetus whose mother has high TRAb titers and uses ATD $[1,11,16]$.

Graves' disease is present in $0.1-1 \%$ of all pregnancies. Fetal or neonatal hyperthyroidism seems to occur in only $1 \%$ of pregnancies in women with Graves' disease $[1,11]$ and is, consequently, a very rare condition but associated with considerable morbidity and mortality $[8,17,19,20]$. Recently, a late referral with high TRAb titers, fetal hyperthyroidism and goiter resulted in fetal death from congestive heart failure at GW 35.5 [11]. In several cases, it is not known that the mother has been treated for Graves' disease $[9,19,20]$, and this may delay correct diagnosis and treatment.

After treatment with radioiodine in Graves' disease, the increase in TRAb seems to peak after 6-12 months, and after 5 years approximately $40 \%$ of patients are still TRAb-positive $[6,7]$. After total thyroidectomy, remission of autoimmunity is more common, although variable. Thus, after 1 year $40-71 \%$ are still TRAb-positive [6, $21,22]$; after 2 years, one study found only $4 \%$ persistent TRAb positivity [23], whereas other studies report TRAb positivity in $10-25 \%$ of patients 5 years after thyroidectomy $[6,21,22]$. In the woman described in this report, we assume that total thyroidectomy had a favorable effect by causing the TRAb level to decline. One similar case of two successive pregnancies in a woman with Graves' disease has been reported, and, as in our report, a beneficial effect from maternal thyroidectomy was observed [10]. Similarly, a prospective study of pregnant women with Graves' disease reported most cases of fetal thyroid dysfunction in the offspring of mothers who had no history of thyroidectomy [11]. After subtotal thyroidectomy, autoimmunity seems to persist in a higher proportion of patients than after total thyroidectomy $[21,22]$, and fetal 
hyperthyroidism caused by persistently elevated TRAb after maternal subtotal thyroidectomy has been described [19].

Thyroidectomy implies a risk of permanent hypoparathyroidism around $0.5-6.6 \%$, and a risk of permanent recurrent laryngeal nerve paresis around 1.5\% [21, 24]. An increased risk for adverse obstetric outcomes was reported in 50 women after total thyroidectomy [25], but the majority were treated for thyroid cancer, and we have not found any report on pregnancy outcome after thyroidectomy in women with Graves' disease. Altogether, in women with Graves' disease who have high TRAb titers and plan pregnancy, the risks associated with thyroidectomy should be balanced against the risks for the fetus and neonate. In case surgical thyroidectomy is performed, adequate replacement therapy with $\mathrm{LT}_{4}$ should be promptly instituted to obtain target pregnancy levels for TSH and optimize fetal development, and conception should preferably be delayed for 6 months [1].
To conclude, we document transplacental passage of TRAb in two successive pregnancies in a woman who received radioiodine treatment for Graves' disease before her first pregnancy and underwent total thyroidectomy before the next pregnancy. The different outcomes in the two neonates obviously reflect the different level of TRAb stimulation in utero. In pregnant women with a history of Graves' disease, previous treatment should be clarified and maternal level of TRAb obtained around 20 weeks of gestation. If TRAb is elevated above three times the ULN, recommendations imply fetal surveillance including echocardiography, intrauterine growth assessment and ultrasound of the fetal thyroid gland.

\section{Disclosure Statement}

The authors have no potential conflicts of interest in connection with this article.

\section{References}

1 Stagnaro-Green A, Abalovich M, Alexander E, Azizi F, Mestman J, Negro R, Nixon A, Pearce EN, Soldin OP, Sullivan S, Wiersinga W: Guidelines of the American Thyroid Association for the diagnosis and management of thyroid disease during pregnancy and postpartum. Thyroid 2011;21:1081-1125.

-2 Polak M, Legac I, Vuillard E, Guibourdenche J, Castanet M, Luton D: Congenital hyperthyroidism: the fetus as a patient. Horm Res 2006;65:235-242.

>3 Laurberg P, Nygaard B, Glinoer D, Grussendorf M, Orgiazzi J: Guidelines for TSH-receptor antibody measurements in pregnancy: results of an evidence-based symposium organized by the European Thyroid Association. Eur J Endocrinol 1998;139:584-586.

-4 Baskin HJ, Cobin RH, Duick DS, Gharib H, Guttler RB, Kaplan MM, Segal RL: American Association of Clinical Endocrinologists medical guidelines for clinical practice for the evaluation and treatment of hyperthyroidism and hypothyroidism. Endocr Pract 2002;8:457-469.

5 Kaplan MM, Meier DA, Dworkin HJ: Treatment of hyperthyroidism with radioactive iodine. Endocrinol Metab Clin North Am 1998;27:205-223.

-6 Laurberg P, Wallin G, Tallstedt L, AbrahamNordling M, Lundell G, Torring O: TSH-receptor autoimmunity in Graves' disease after therapy with anti-thyroid drugs, surgery, or radioiodine: a 5-year prospective randomized study. Eur J Endocrinol 2008;158: 69-75.
7 Chiappori A, Villalta D, Bossert I, Ceresola EM, Lanaro D, Schiavo M, Bagnasco M, Pesce G: Thyrotropin receptor autoantibody measurement following radiometabolic treatment of hyperthyroidism: comparison between different methods. J Endocrinol Invest 2010;33:197-201.

$\checkmark 8$ Hamada N, Momotani N, Ishikawa N, Yoshimura Noh J, Okamoto Y, Konishi T, Ito K: Persistent high TRAb values during pregnancy predict increased risk of neonatal hyperthyroidism following radioiodine therapy for refractory hyperthyroidism. Endocr J 2011;58:55-58.

-9 Towers CV, Thomas S, Steiger RM: The fetal heart monitor tracing in pregnancies complicated by fetal thyrotoxicosis. Am J Perinatol 2009;26:373-377.

10 Zuppa AA, Sindico P, Savarese I, D’Andrea V, Fracchiolla A, Cota F, Romagnoli C: Neonatal hyperthyroidism: neonatal clinical course of two brothers born to a mother with Graves-Basedow disease, before and after total thyroidectomy. J Pediatr Endocrinol Metab 2007;20:535-539.

11 Luton D, Le Gac I, Vuillard E, Castanet M, Guibourdenche J, Noel M, Toubert ME, Leger J, Boissinot C, Schlageter MH, Garel C, Tebeka B, Oury JF, Czernichow P, Polak M: Management of Graves' disease during pregnancy: the key role of fetal thyroid gland monitoring. J Clin Endocrinol Metab 2005; 90:6093-6098.
12 Laurberg P, Bournaud C, Karmisholt J, Orgiazzi J: Management of Graves' hyperthyroidism in pregnancy: focus on both maternal and foetal thyroid function, and caution against surgical thyroidectomy in pregnancy. Eur J Endocrinol 2009;160:1-8.

13 Niklasson A, Ericson A, Fryer JG, Karlberg J, Lawrence C, Karlberg P: An update of the Swedish reference standards for weight, length and head circumference at birth for given gestational age (1977-1981). Acta Paediatr Scand 1991;80:756-762.

14 Sinclair D: Analytical aspects of thyroid antibodies estimation. Autoimmunity $2008 ; 41$ : 46-54.

15 Kamijo K: TSH-receptor antibodies determined by the first, second and third generation assays and thyroid-stimulating antibody in pregnant patients with Graves' disease. Endocr J 2007;54:619-624.

16 Polak M: Thyroid disorders during pregnancy: impact on the fetus. Horm Res Paediatr 2011;76(suppl 1):97-101.

17 McNab T, Ginsberg J: Use of anti-thyroid drugs in euthyroid pregnant women with previous Graves' disease. Clin Invest Med 2005;28:127-131.

18 Kubota S, Ohye H, Sasaki I, Nishihara E, Kudo T, Fukata S, Amino N, Kuma K, Mitsuda N, Miyauchi A: Successful use of iodine and levothyroxine to treat Graves' disease in a pregnant patient with allergy to antithyroid drugs and high thyrotropin-binding inhibitor immunoglobulin after radioiodine therapy. Thyroid 2005;15:1373-1376. 
19 Polak M, Leger J, Luton D, Oury JF, Vuillard E, Boissinot C, Czernichow P: Fetal cord blood sampling in the diagnosis and the treatment of fetal hyperthyroidism in the offsprings of a euthyroid mother, producing thyroid stimulating immunoglobulins. Ann Endocrinol (Paris) 1997;58:338342.

-20 Lewis KA, Engle W, Hainline BE, Johnson N, Corkins M, Eugster EA: Neonatal Graves' disease associated with severe metabolic abnormalities. Pediatrics 2011;128:e232-e236.
21 Barczynski M, Konturek A, HubalewskaDydejczyk A, Golkowski F, Nowak W: Randomized clinical trial of bilateral subtotal thyroidectomy versus total thyroidectomy for Graves' disease with a 5-year follow-up. Br J Surg 2012;99:515-522.

22 Takamura Y, Nakano K, Uruno T, Ito Y, Miya A, Kobayashi K, Yokozawa T, Matsuzuka F, Kuma K, Miyauchi A: Changes in serum TSH receptor antibody (TRAb) values in patients with Graves' disease after total or subtotal thyroidectomy. Endocr J 2003;50:595-601.
23 De Bellis A, Conzo G, Cennamo G, Pane E, Bellastella G, Colella C, Iacovo AD, Paglionico VA, Sinisi AA, Wall JR, Bizzarro A, Bellastella A: Time course of Graves' ophthalmopathy after total thyroidectomy alone or followed by radioiodine therapy: a 2-year longitudinal study. Endocrine 2012;41:320-326.

24 Shoback D: Clinical practice. Hypoparathyroidism. N Engl J Med 2008;359:391-403.

25 Cohen N, Levy A, Wiznitzer A, Sheiner E: Perinatal outcomes in post-thyroidectomy pregnancies. Gynecol Endocrinol 2011;27: 314-318. 